To the Editors:

\title{
Poncet's disease or tuberculous rheumatism
}

Ceylon Medical Journal 2011; 56: 43-44

Poncet's disease or tuberculous rheumatism, first described by Poncet in 1897, is a rare form of polyarthritis resulting from visceral tuberculosis without any direct involvement of the joints [1].

A 16-year old girl had low to moderate grade fever and joint pain for 3 months. Her joints were swollen without signs of inflammation. This involved almost all joints of the body both small and large. At times the joint pain was severely incapacitating.

On examination, she was anicteric and had pallor. The liver was marginally enlarged. Her joints, particularly the knee and small joints of hand, were painful on palpation. Chest examination was normal except for occasional crepitations in the right infrascapular region.

Her investigations were as follows: haemoglobin $8.7 \mathrm{~g} / \mathrm{dl}$, total leukocyte count $-7.7 \times 10 \mathrm{~g} / \mathrm{l}$ neutrophils $52 \%$, lymphocytes $-44 \%$, platelet count $-255 \times 10 \mathrm{~g} / \mathrm{l}$, ESR
- $80 \mathrm{~mm}$ in 1st hour, marginally raised liver enzymes and raised serum globulin $50 \mathrm{~g} / \mathrm{l}$ against a normal serum albumin $38 \mathrm{~g} / \mathrm{l}$. The chest X-ray showed few suspicious shadows in the left apical area and abdominal ultrasonography showed marginally enlarged liver without intra abdominal lymphadenopathy. Routine urine examination, culture and serum creatinine values were normal.

Though the sputum for acid-fast bacilli was negative, sputum was sent for tuberculosis culture. Rheumatoid factor, serum uric acid, HIV serology and ASO were normal. The CRP was only marginally elevated (1.72). Mantoux test was highly reactive $(18 \mathrm{~mm})$ at 72 hours. Synovial fluid analysis from the left knee joint was normal. Considering the elevated ESR, positive Mantoux test raised serum globulins and ALP and suspicious infiltrates on chest X-ray with negative serology a presumptive diagnosis of tuberculous rheumatism was made. The patient was started on antitubercular therapy. The patient stayed in hospital for 
two months. Her joint pain subsided 3 weeks after starting therapy and she became afebrile soon thereafter. At this time, the sputum for mycobacterial culture report arrived as positive. At follow up she was doing well with her body weight haemoglobin and chest X-ray improved.

Poncet's disease is a polyarthritis occurring during active tuberculosus infection with no mycobacterial involvement found in the joints or other known cause of polyarthritis detected. It is different from tuberculous arthritis, which is usually monoarticular and is caused by direct tuberculous infection. Poncet's disease remains a diagnosis of exclusion [2]. The existence of this entity has always been a matter of debate with opinions divided for and against the tuberculous aetiology [2,3]. Treatment is with standard antitubercular therapy. Joint pain subsides in a few weeks and does not recur.

\section{References}

1. Poncet A, Tuberculous rheumatism. Congres Francais de Chirurge 1897; 1: 732-7.

2. Dall L, Long L, Stanford J. Poncet's disease: tuberculous rheumatism. Review of Infectious Diseases 1989; 2: 105-7.

3. Issacs AJ, Sturrock RD. Poncet's disease - fact or fiction? Tubercle 1974; 55:135-42.

\section{P Singhania ${ }^{1}$, A Banerjee ${ }^{1}$, B Singhania ${ }^{1}$, I Banerjee ${ }^{1}$, V Kumar $^{1}$, S Maitra ${ }^{1}$}

${ }^{1}$ Department of Medicine, Medical College, Kolkata, India.

Correspondence: PS, e-mail <drpankaj007@hotmail.com>. Received 20 May and revised version accepted 12 November 2010. Competing interests: none declared. 